\title{
Imaging of Acute Ischemic Stroke
}

\author{
Marwan El-Koussy ${ }^{\mathrm{a}}$ Gerhard Schroth $^{\mathrm{a}}$ Caspar Brekenfeld $^{\mathrm{c}}$ Marcel Arnold $^{\mathrm{b}}$ \\ anstitute of Diagnostic and Interventional Neuroradiology, ${ }^{\mathrm{b}}$ Department of Neurology, University Hospital Bern, \\ Bern, Switzerland; ' Department of Neuroradiology, University Hospital Eppendorf Hamburg, Hamburg, Germany
}

\section{Key Words}

Stroke $\cdot$ Penumbra $\cdot$ Imaging

\begin{abstract}
Background: Over $80 \%$ of strokes result from ischemic damage to the brain due to an acute reduction in the blood supply. Around $25-35 \%$ of strokes present with large vessel occlusion, and the patients in this category often present with severe neurological deficits. Without early treatment, the prognosis is poor. Stroke imaging is critical for assessing the extent of tissue damage and for guiding treatment. Summary: This review focuses on the imaging techniques used in the diagnosis and treatment of acute ischemic stroke, with an emphasis on those involving the anterior circulation. Key Message: Effective and standardized imaging protocols are necessary for clinical decision making and for the proper design of prospective studies on acute stroke. Clinical Implications: Each minute without treatment spells the loss of an estimated 1.8 million neurons ('time is brain'). Therefore, stroke imaging must be performed in a fast and efficient manner. First, intracranial hemorrhage and stroke mimics should be excluded by the use of computed tomography (CT) or magnetic resonance imaging (MRI). The next key step is to define the extent and location of the infarct core (values of $>70 \mathrm{ml},>1 / 3$ of the middle cerebral artery (MCA) territory
\end{abstract}

or an ASPECTS score $\leq 7$ indicate poor clinical outcome). Penumbral imaging is currently based on the mismatch concept. It should be noted that the penumbra is a dynamic zone and can be sustained in the presence of good collateral circulation. A thrombus length of $>8 \mathrm{~mm}$ predicts poor recanalization after intravenous thrombolysis.

C 2014 S. Karger AG, Basel

\section{Introduction}

Stroke is a major cause of mortality and long-term disability. More than $80 \%$ of strokes stem from ischemic damage to the brain due to the acute reduction of the blood supply. It was calculated that 1.8 million neurons are lost every minute that appropriate treatment is not given ('time is brain') [1]. For these reasons, 'stroke imaging' is crucial and has to be performed in a fast and efficient manner (fig. 1).

About 25-35\% of strokes present with large vessel occlusion. Patients who fall within this category often present with severe neurological deficits and prognosis is often poor if early treatment is not possible. This group is thus the major target for endovascular interventions. Recent studies have postulated no significant differences between reperfusion strategies [2]. Appropriate patient se-

\section{KARGER}

E-Mail karger@karger.com

www.karger.com/ene
(C) 2014 S. Karger AG, Basel

0014-3022/14/0726-0309\$39.50/0
Marcel Arnold, MD

Department of Neurology

University Hospital of Bern, Inselspital

CH-3010 Bern (Switzerland)

E-Mail marcel.arnold@insel.ch 
Fig. 1. Pathophysiology of stroke: The occlusion of the artery leads to hypoperfusion of the tissue segment supplied by that vessel. The affected parenchyma usually consists of a severely hypoperfused (CBF $\leq 10 \mathrm{ml} / 100$ $\mathrm{g} / \mathrm{min}$ ) central infarct core where the damage is irreversible. It is bordered by the critically hypoperfused (CBF 10-20 ml/100 $\mathrm{g} / \mathrm{min}$ ) ischemic penumbra (tissue-at-risk), where the injury may be reversed if timely reperfusion occurs. Collaterals aim at preserving as much penumbral tissue as possible. With time (minutes to hours) the infarct core expands at the expense of the penumbra. This is also helped by its mass effect on the neighbouring arteries. The penumbra is surrounded by tissue which is not at risk of infarction, the so-called 'benign oligemia' (CBF > $20 \mathrm{ml} / 100 \mathrm{~g} / \mathrm{min}$ ).

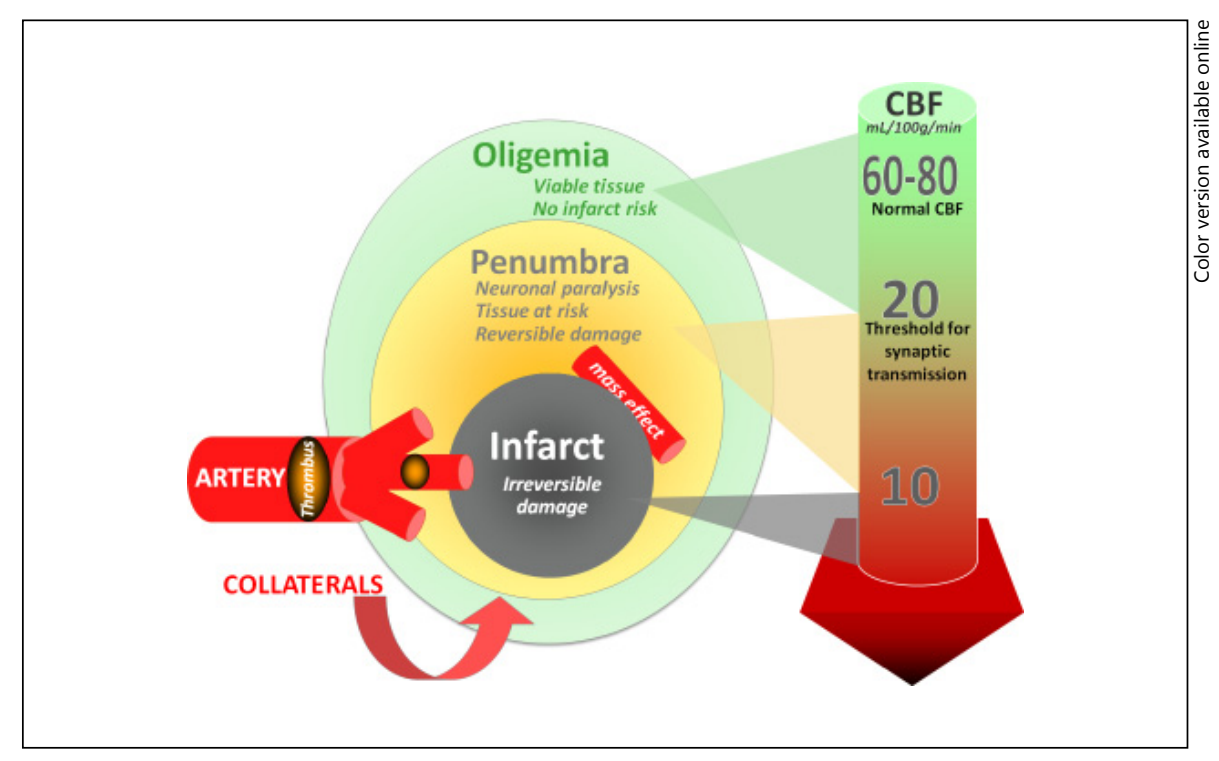

lection based on clinical findings and neuroimaging is crucial [3]. Effective and standardized imaging protocols are necessary for clinical decision making and for proper design of prospective studies on acute stroke. This review focuses on acute ischemic stroke involving the anterior circulation.

\section{Stroke Imaging}

Stroke imaging can be done using either computed tomography (CT) or magnetic resonance imaging (MRI). The choice is based mostly on the available infrastructure and staff, as well as the experience of the stroke team. $\mathrm{CT}$ is the imaging workhorse available in most hospitals on a round-the-clock basis. Use of CT imaging can readily exclude the presence of an acute cerebral hemorrhage. The recent technical advancements in CT and its speed confer additional advantages to this technique. Radiation exposure remains a relevant issue in stroke CT, especially if contrast-angiography and perfusion-CT datasets are acquired. Some institutions have MRI available at all times and prefer it over CT for many patients due to the additional information it provides (as described later).

Before scanning the (neuro-)radiologist needs to possess certain clinical information, that is, onset of the symptoms, the clinical findings including the NIHSS score and relevant patient history. The main goals of imaging are (1) to rule out intracranial hemorrhage, (2) to define the extent of the ischemic damage and to differentiate between the infarct core and the salvageable ischemic penumbra, and (3) to visualize the vessel status. We will describe the imaging steps based on the sequence of the images acquired on CT or MRI.

\section{The Role of Imaging in the Clinical Management of Acute Ischemic Stroke}

\section{Step 1: Rule Out Other Lesions}

Rule out intracranial hemorrhage $(\mathrm{ICH})$ or other space-occupying mass lesions, for example, neoplasms. An acute ICH can be classically detected as a lesion with high CT density (60-90 HU) and with a high sensitivity. T2*-gradient-echo MRI sequences are extremely sensitive for detecting ICH [4].

\section{Step 2: Define the Infarct Core (IC)}

Defining the extent and location of the ischemic parenchyma irreversibly damaged by the significant hypoperfusion, the 'infarct core', is the primary step that guides further therapy. With ischemia (defined as cerebral blood flow [CBF] below $10-12 \mathrm{ml} / 100 \mathrm{~g} / \mathrm{min}$ ) $[5,6]$ and consequent energy failure, water molecules are trapped in the affected cells, a process called 'compartmentalization'; this leads to the development of cytotoxic edema. The latter can be seen as a decrease in tissue density (hypodensity) on CT and is considered to be the marker of an IC (fig. 2a). For each 1\% increase in tissue 
Fig. 2. CT in acute stroke. The patient presented with an acute onset of left-sided hemiparesis and neglect; NIHSS score was 13. CT performed $3.5 \mathrm{~h}$ after symptom onset (a) showed subtle hypodensity (white arrow) in the anterior part of the middle cerebral artery (MCA) territory. CT angiography (b) revealed an occlusion of the M2 superior branch of the left MCA. Timeto-peak perfusion map (c) reveals the extent of delayed perfusion in the affected MCA territory, nearly similar to the extent of the hypoperfusion seen on the cerebral blood flow map (d). The parenchyma with cerebral blood volume (e) reduction gives a good estimate of the irreversibly infarcted core. The occlusion was successfully treated with endovascular mechanical thrombectomy. The infarct is depicted on the 4-day follow-up scan (f).
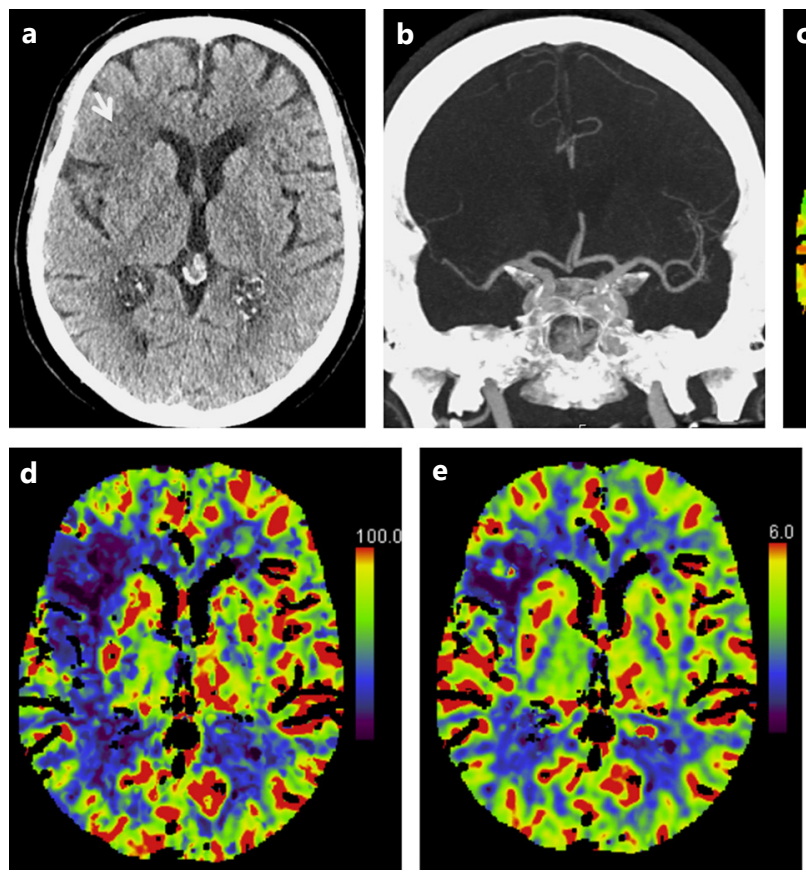
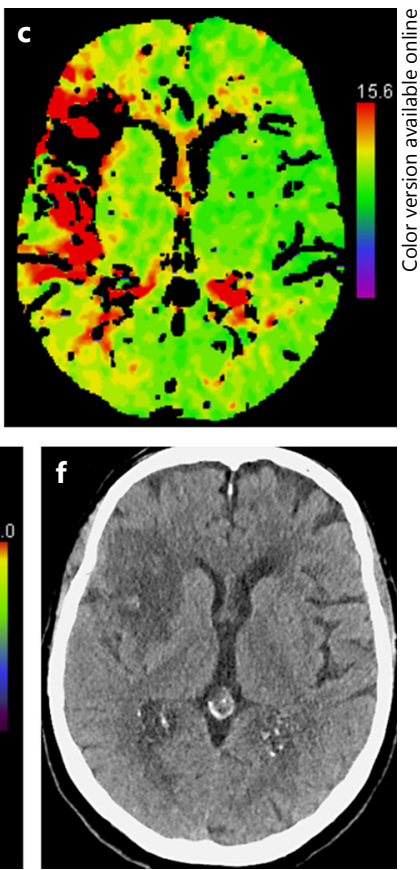

water content, a decrease in tissue density of 2.6 Hounsfield Units is observed [7]. Early ischemic signs due to edema include blurring of the clarity of the internal capsule, loss of distinctness of the insular ribbon cortex and loss of cortico-medullary differentiation. The CT signs have a sensitivity of $40-60 \%$ within the first $3 \mathrm{~h}$ after symptom onset and have specificity, positive and negative predictive values of 85,96 and $27 \%$, respectively. The earliest time for detecting the hypodensity due to ischemia is about $45 \mathrm{~min}[8,9]$. With MRI, diffusion-weighted imaging (DWI) is the tool used to define IC. DWI detects cytotoxic edema due to the restricted motion of the water molecules trapped in the cell [10]. This restricted diffusion is seen as a bright signal on b1000 DWI images or as a low signal on the corresponding, automatically calculated apparent diffusion coefficient (ADC) maps (fig. 3a, b and h). An ADC $\leq 620 \times 10^{-6} \mathrm{~mm}^{2} / \mathrm{s}$ was proposed as the threshold for identification of IC (with a sensitivity of $69 \%$ and a specificity of $78 \%$ ) [11]. DWI can detect ischemia as early as 11 minutes after stroke onset [12], and is much more sensitive than CT for the identification of acute ischemia [13]. However, some areas with restricted diffusion may show reversal of these changes and thus are considered being part of the penumbra [14].

The extent of ischemic damage as detected on CT or MRI can be measured by eye-balling, semiquantitatively, that is, with the ASPECTS score [15], or with volumetry. For anterior circulation stroke, a large infarct affecting more than $1 / 3$ of the territory of the middle cerebral artery, larger than $100 \mathrm{ml}$ (or even $70 \mathrm{ml}$ [16]) or declining to 7 points or less on the ASPECTS score is a predictor of poor clinical outcome and thus negatively affects the selection of patients for thrombolysis $[9,15,17]$. A similar concept can be applied to posterior circulation strokes. Thus, worse prognosis is observed for brainstem infarcts, especially for those affecting the pyramidal tract as well as large infarcts affecting more than $1 / 3$ of the cerebellar hemispheres resulting in the compression of the fourth ventricle and hydrocephalus [18]. We are often faced with patients presenting with a wake-up stroke of unknown symptom onset. In such patients, a clearly hyperintense ischemia on T2-weighted and FLAIR MRI is considered a marker of IC (fig. $3 \mathrm{c}$ and i). In such cases, stroke experts are usually cautious to initiate a thrombolytic therapy [19].

\section{Step 3: Penumbral Imaging}

The ischemic penumbra [5], the 'tissue-at-risk' represents the critically hypoperfused (CBF $12-20 \mathrm{ml} / 100$ $\mathrm{g} / \mathrm{min}$ ) parenchyma suffering neuronal silence and thus also causes neurological deficits. This functional damage can be reversed if timely reperfusion occurs. Otherwise, more and more of the penumbra will be recruited to the 


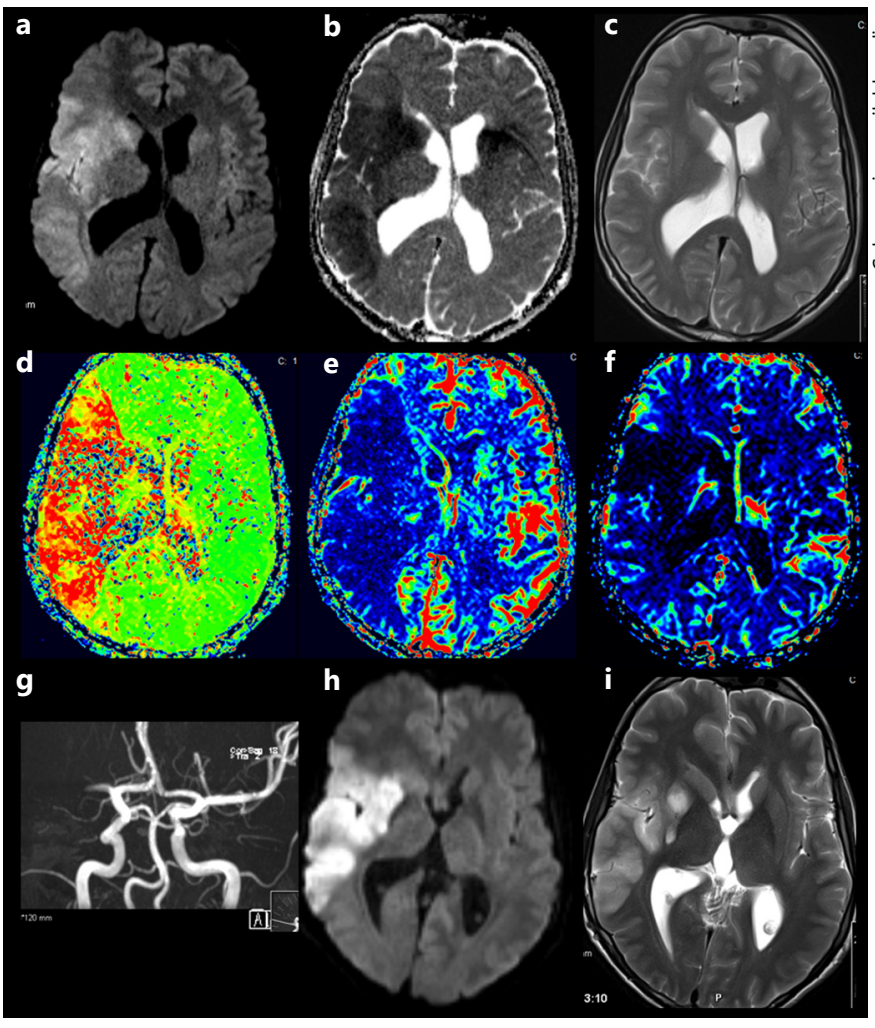

Fig. 3. Classical stroke MRI of a hyperacute MCA occlusion on the right side. Diffusion-weighted b1000 image (a) clearly shows the area of acute ischemia as a bright signal. This is confirmed by the automatically generated apparent diffusion coefficient map (b) demonstrating the true restricted diffusion of the water molecules as a low signal. The hyperacute ischemia is not yet detectable on the conventional T2-weighted image (c). The perfusion time-topeak map (d) reveals the area of delayed perfusion which suffers low cerebral blood flow (e). The cerebral blood volume is diminished in the irreversibly injured tissue seen as signal drop on the corresponding map (f). The occlusion of the M1-segment is clearly depicted on the time-of-flight MR-Angiography $(\mathbf{g})$. The $24 \mathrm{~h}-$ follow-up shows the ultimate extent of the infarction on the diffusion- (h) and T2-weighted (i) images.

IC. Thus, we need to think of penumbra as a dynamic region [20]. Discriminating the IC from the penumbra and from the surrounding benign oligemia ('tissue-not-atrisk'; $\mathrm{CBF}>20 \mathrm{ml} / 100 \mathrm{~g} / \mathrm{min}$ ) requires the application of CT- or MR-perfusion imaging (CTP or PI respectively). Both techniques are dynamic imaging techniques necessitating the administration of intravenous contrast medium and yielding several parameter maps. The latter can be divided into (a) time maps, for example, time-to-maximum (Tmax), time-to-peak (TTP) and mean-transittime (MTT), as well as the (b) cerebral blood flow (CBF) and $(\mathrm{c})$ volume $(\mathrm{CBV})$ maps. The reduced $\mathrm{CBF}$ in the pen- umbra triggers energy-dependent autoregulatory mechanisms to keep the CBV normal or even slightly elevated accompanied by elevated MTT and TTP. These compensatory mechanisms fail in the IC causing a CBV drop. Thus, CBV drop is a marker of infarction and correlates with the diffusion restriction only in hyperacute stroke [21] (fig. 2c-e and fig. 3d-f). The penumbra is traditionally defined on MRI as the area of DWI $<$ PI mismatch. For PI, a Tmax with a delay of $>6 \mathrm{~s}$ and $>10 \mathrm{~s}$ has been used recently in large stroke trials, for instance, DEFUSE2, to define the thresholds for penumbra and IC, respectively [22]. TTP and MTT are also good alternatives to Tmax in determining the diffusion/perfusion mismatch. In CT, a mismatch between CBV (threshold at $2.0 \mathrm{ml} / 100 \mathrm{~g}$ for IC) and MTT (threshold at a relative MTT of $145 \%$ for the tissue at risk of infarction) defines the ischemic penumbra [23]. Almost all cases with an anterior circulation stroke show mismatch within the first $3 \mathrm{~h}$. This declines to $75 \%$ within the first $6 \mathrm{~h}$ and to $50 \% 12-18 \mathrm{~h}$ after onset [24]. It has to be noted that the post-processing techniques used for the perfusion-CT and MRI analyses are not standardized, and can lead to variation in perfusion lesions of $50 \%$ or more [25]. In a recent study, academic programs outperformed commercial perfusion software [26]. The diffusion/perfusion mismatch concept is currently considered by several authors as inadequate for patient selection in ischemic stroke treatment trials [27]. Several experts suggest that the indication for endovascular intervention is set in case of severe neurological deficit, presence of a large vessel occlusion and a small $(<70 \mathrm{ml})$ infarct core. Thus, the necessity of perfusion imaging for therapeutic decision making has to be proven [28]. Such issues are addressed by automated software solutions and consortia of stroke imaging specialists, for example, STIR [29, 30]. Several brain regions are known to have the highest ischemic vulnerability. These include the caudate body, putamen nucleus, and insular ribbon as well as selected areas of the frontal lobe including the middle frontal gyrus, precentral gyrus, paracentral lobule and the subcortical white matter [31].

\section{Step 4: Arterial Imaging}

4.1. Arterial lumen imaging is achieved by CT- or MRangiography (fig. 2b). The scan has to cover the entire arterial tree from the aortic arch to the vertex [32]. MRI provides the advantage of noncontrast imaging of the intracranial arteries using the flow-sensitive time-offlight (TOF) technique (fig. 3g). The combined assessment of the intracranial and extracranial cervical arteries provides a true 'lumenography' and requires automated 
injection of intravenous contrast medium using an injection pump. The fast scanning protocols are timed to optimize the acquisition in the arterial phase. The following points are important to comment upon: a) site of occlusion; this is of utmost importance since large vessel occlusions produce severe neurological symptoms and eventually result in poor outcomes. Mortality rates for distal ICA, proximal MCA and basilar artery occlusions are reported at $41.7-53 \%$ [33-35], 27-78\% [36, 37] and 92\% [38], respectively. b) Details of collateral circulation are of particular importance since the extent of collateralization is a predictor of final infarct volume and thus the clinical outcome [39]. It was shown that the rate of neuronal loss varies greatly depending on the state of the collaterals, which can maintain a stable penumbra for several hours after the onset of occlusion [40]. Several grading systems for the collateral circulation have been proposed [41]. Furthermore, c) tandem occlusions or stenosis and d) anatomical peculiarities that can handicap or modify the technique of the endovascular intervention, for example, arterial loops, angulated origin of the artery, can be documented.

4.2. Dissection: Fat-suppressed T1-weighted MRI images are the gold standard to visualize the mural hematoma in cases of arterial dissection [42] (fig. 4). In addition, contrast-enhanced CT- or MR-angiography may detect the dissection membrane. Enhancement of the arterial wall distal to the arterial occlusion, the so-called 'carotid ring sign' can indicate a recent ( $<1$ week) arterial occlusion [43].

4.3. The acute thrombus can be seen on noncontrast CT as a (hyper)dense artery sign [44-46] or on $\mathrm{T} 2 *$-gradientecho MR imaging, including the more sensitive susceptibility-weighted imaging (SWI) as an MRI signal drop, the so-called 'artery susceptibility sign' [47] (fig. 5b). A recent study has shown that a dense middle cerebral artery longer than $8 \mathrm{~mm}$ predicts poor recanalization after intravenous thrombolysis [48]. The quantification of the extent of the intracranial thrombus using the clot burden score predicts final infarct size and functional outcome [49].

4.4. Other 'vessel signs': SWI not only depicts the thrombus, but it demonstrates additional vessel 'signs'. The increased oxygen extraction in the ischemic tissue leads to a local increase in deoxy-hemoglobin, which in turn causes the so-called BOLD (blood oxygen level dependent) effect, which is a commonly used functional MRI technique. In acute major vessel occlusion SWI, formerly called 'venous BOLD' imaging, prominent, low-signal vessels are visible in the hypoperfused area. These are seen peripherally ('cortical vessel sign' or 'abnormal visualization of leptomeningeal vessels') in the deep white matter

Imaging of Acute Ischemic Stroke
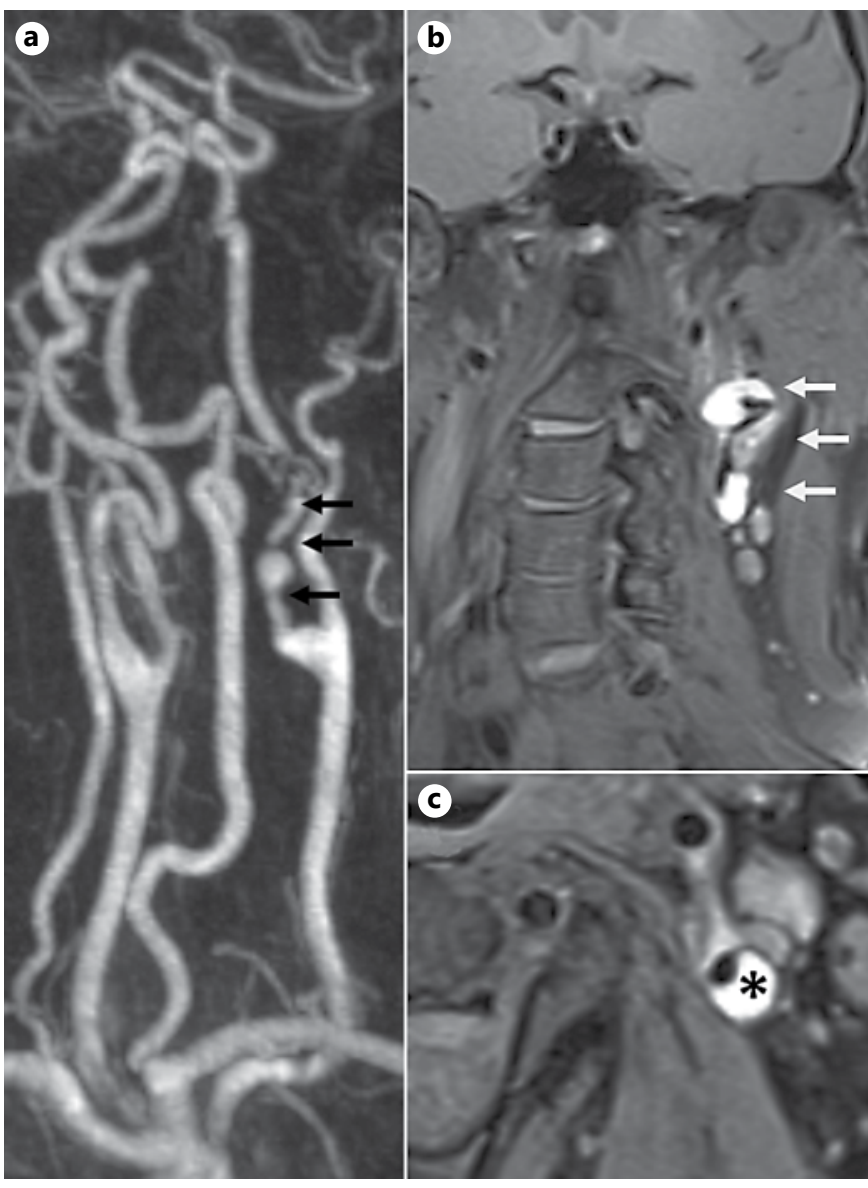

Fig. 4. Carotid dissection on the left side seen on the first-pass contrast-enhanced MR-Angiography (a) as vessel irregularities (black arrows) of the proximal cervical segment. Pre-contrast fatsuppressed, T1-weighted coronal (b) image shows the mural hematoma as a bright signal (white arrows). The corresponding axial image (c) demonstrates the classical appearance of a spindleshaped bright mural hematoma (asterisk).

('brush sign') (fig. 5c). Collectively both were termed the 'region of multiple hypointense vessels (RMHV).' Before SWI was widely used in the clinical stroke MRI routine, the same findings were described with the T2* gradientecho imaging $[50,51]$. The reversal of the cortical vessel sign has been observed after full recanalization and is associated with a favorable outcome [52].

\section{Step 5: Miscellaneous}

5.1. Prediction of hemorrhagic transformation in an infarction can be achieved by observing the hyperintensity of the CSF space on FLAIR-MRI or parenchymal enhancement after intravenous administration of gadolinium $[53,54]$. 
Fig. 5. Role of susceptibility-weighted imaging. The measurement of the occluding thrombus in the right middle cerebral artery documented by the catheter angiography (a) is very near to that obtained by the SWI (b). Note how well the thrombus (white arrowheads) is seen on SWI as an ovoid area of signal drop. SWI also depicts the low-signal prominent cortical veins (white arrowheads) and the brush sign (asterisk) (c).
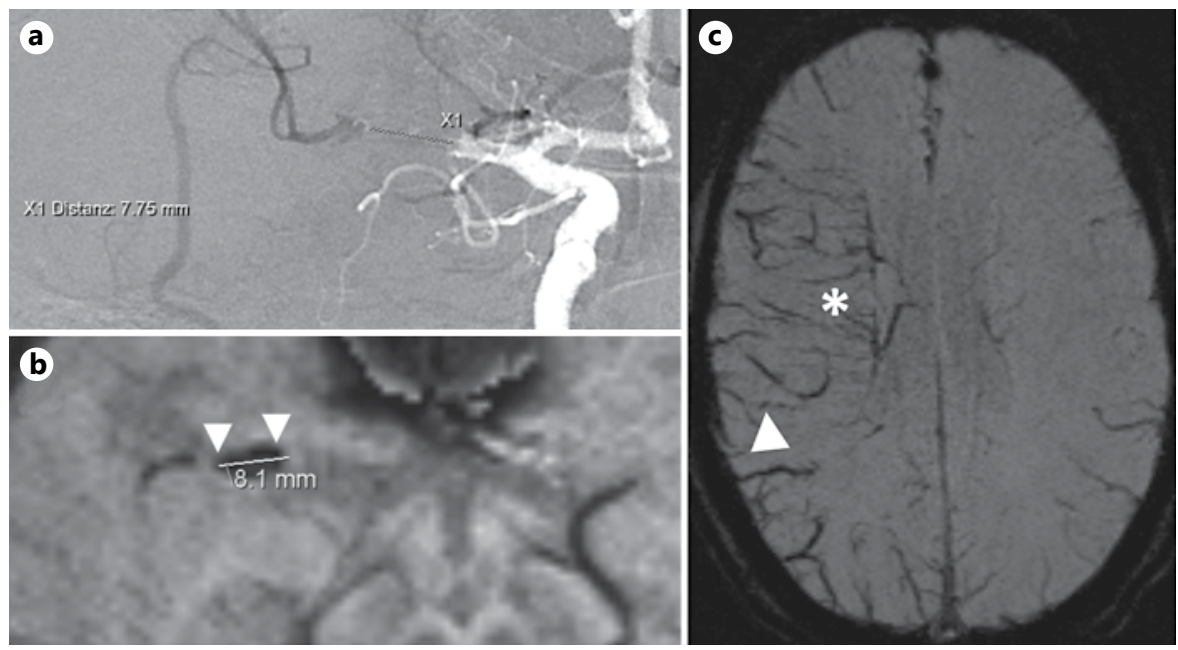

5.2. Presence of cerebral microbleeds does not seem to lead to a relevant increase in symptomatic ICH and thus appears to be a contraindication for thrombolytic therapy [55].

5.3. Future trends in imaging include the arterial spin labeling (ASL) perfusion MRI, a technique that provides quantifiable CBF maps without the need to administer intravenous contrast medium. Recent publications have demonstrated the feasibility and usefulness of this method if combined with the other stroke MR sequences [56]. A special ASL method, the so-called 'territorial arterial spin labeling' can provide insight on collateral circulation in patients who may not otherwise be candidates for digital subtraction angiography [57].

\section{Conclusion}

The recent advances in stroke imaging allow almost real-time information on many aspects of stroke pathophysiology. The main role of imaging is to exclude an intracranial hemorrhage, define the ischemic region, to distinguish between infarct core and penumbra and to depict the vessel status. CT and MRI are modalities that can be used with confidence, both having their strengths and weaknesses. CT is more widely available but MRI can provide additional information and is more sensitive to small infarctions. The choice of modality depends on the infrastructure, the logistics, the expertise as well as the scientific interest of the stroke team.

\section{References}

1 Saver JL: Time is brain-quantified. Stroke 2006;37:263-266.

2 Kidwell CS, Jahan R, Gornbein J, Alger JR, Nenov V, Ajani Z, et al: A trial of imaging selection and endovascular treatment for ischemic stroke. N Engl J Med 2013;368:914-923.

3 Gonzalez RG: Low signal, high noise and large uncertainty make CT perfusion unsuitable for acute ischemic stroke patient selection for endovascular therapy. J Neurointerv Surg 2012; $4: 242-245$.

4 Kidwell CS, Chalela JA, Saver JL, Starkman S, Hill MD, Demchuk AM, et al: Comparison of MRI and CT for detection of acute intracerebral hemorrhage. JAMA 2004;292:1823-1830.

5 Astrup J, Siesjo BK, Symon L: Thresholds in cerebral ischemia - the ischemic penumbra. Stroke 1981;12:723-725.
Heros RC: Stroke: early pathophysiology and treatment. Summary of the Fifth Annual Decade of the Brain Symposium. Stroke 1994;25: 1877-1881.

7 Unger E, Littlefield J, Gado M: Water content and water structure in CT and MR signal changes: possible influence in detection of early stroke. AJNR Am J Neuroradiol 1988;9: 687-691.

$>8$ Tissue plasminogen activator for acute ischemic stroke: The National Institute of Neurological Disorders and Stroke rt-PA Stroke Study Group. N Engl J Med 1995;333:15811587.

-9 Hacke W, Kaste M, Fieschi C, Toni D, Lesaffre $\mathrm{E}$, von Kummer R, et al: Intravenous thrombolysis with recombinant tissue plasminogen activator for acute hemispheric stroke. The European Cooperative Acute Stroke Study (ECASS). JAMA 1995;274: 1017-1025.

10 Lovblad KO, Baird AE, Schlaug G, Benfield A, Siewert B, Voetsch B, et al: Ischemic lesion volumes in acute stroke by diffusion-weighted magnetic resonance imaging correlate with clinical outcome. Ann Neurol 1997;42:164170.

-11 Purushotham A, Campbell BC, Straka M, Mlynash M, Olivot JM, Bammer R, et al: Apparent diffusion coefficient threshold for delineation of ischemic core. Int J Stroke 2013, DOI: $10.1111 /$ ijs. 12068 .

$\checkmark 12$ Hjort N, Christensen S, Solling C, Ashkanian $\mathrm{M}, \mathrm{Wu} \mathrm{O}$, Rohl L, et al: Ischemic injury detected by diffusion imaging 11 minutes after stroke. Ann Neurol 2005;58:462-465. 
13 Barber PA, Darby DG, Desmond PM, Gerraty RP, Yang Q, Li T, et al: Identification of major ischemic change. Diffusion-weighted imaging versus computed tomography. Stroke 1999;30:2059-2065.

-14 Kidwell CS, Saver JL, Mattiello J, Starkman S, Vinuela F, Duckwiler G, et al: Thrombolytic reversal of acute human cerebral ischemic injury shown by diffusion/perfusion magnetic resonance imaging. Ann Neurol 2000;47: 462-469.

-15 Pexman JH, Barber PA, Hill MD, Sevick RJ, Demchuk AM, Hudon ME, et al: Use of the Alberta Stroke Program Early CT Score (ASPECTS) for assessing CT scans in patients with acute stroke. AJNR Am J Neuroradiol 2001;22:1534-1542.

-16 Yoo AJ, Barak ER, Copen WA, Kamalian S, Gharai LR, Pervez MA, et al: Combining acute diffusion-weighted imaging and mean transmit time lesion volumes with National Institutes of Health Stroke Scale Score improves the prediction of acute stroke outcome. Stroke 2010;41:1728-1735.

-17 von Kummer R, Allen KL, Holle R, Bozzao L, Bastianello S, Manelfe C, et al: Acute stroke: usefulness of early CT findings before thrombolytic therapy. Radiology 1997;205:327-333.

- 18 Karameshev A, Arnold M, Schroth G, Kappeler L, Stein P, Gralla J, et al: Diffusionweighted MRI helps predict outcome in basilar artery occlusion patients treated with intra-arterial thrombolysis. Cerebrovasc Dis 2011;32:393-400.

19 Bai Q, Zhao Z, Fu P, Sui H, Xie X, Chen J, et al: Clinical outcomes of fast MRI-based thrombolysis in wake-up strokes compared to superacute ischemic strokes within 12 hours. Neurol Res 2013;35:492-497.

$\checkmark 20$ Heiss WD, Graf R: The ischemic penumbra. Curr Opin Neurol 1994;7:11-19.

-21 Knash M, Tsang A, Hameed B, Saini M, Jeerakathil T, Beaulieu C, et al: Low cerebral blood volume is predictive of diffusion restriction only in hyperacute stroke. Stroke 2010;41: 2795-2800.

22 Lansberg MG, Straka M, Kemp S, Mlynash M, Wechsler LR, Jovin TG, et al: MRI profile and response to endovascular reperfusion after stroke (DEFUSE 2): a prospective cohort study. Lancet Neurol 2012;11:860867.

23 Wintermark M, Flanders AE, Velthuis B, Meuli R, van Leeuwen M, Goldsher D, et al: Perfusion-CT assessment of infarct core and penumbra: receiver operating characteristic curve analysis in 130 patients suspected of acute hemispheric stroke. Stroke 2006;37: 979-985.

24 Darby DG, Barber PA, Gerraty RP, Desmond PM, Yang Q, Parsons M, et al: Pathophysiological topography of acute ischemia by combined diffusion-weighted and perfusion MRI. Stroke 1999;30:2043-2052.

-25 Kane I, Carpenter T, Chappell F, Rivers C, Armitage $\mathrm{P}$, Sandercock $\mathrm{P}$, et al: Comparison of 10 different magnetic resonance perfusion imaging processing methods in acute ischemic stroke: effect on lesion size, proportion of patients with diffusion/perfusion mismatch, clinical scores, and radiologic outcomes. Stroke 2007;38:3158-3164.

26 Kudo K, Christensen S, Sasaki M, Ostergaard L, Shirato H, Ogasawara K, et al: Accuracy and reliability assessment of $\mathrm{CT}$ and MR perfusion analysis software using a digital phantom. Radiology 2012;267:201-211.

27 Schabitz WR: MR mismatch is useful for patient selection for thrombolysis: no. Stroke 2009;40:2908-2909.

28 Gonzalez RG: Clinical MRI of acute ischemic stroke. J Magn Reson Imaging 2012;36:259271.

29 Lansberg MG, Lee J, Christensen S, Straka M, De Silva DA, Mlynash M, et al: RAPID automated patient selection for reperfusion therapy: a pooled analysis of the Echoplanar Imaging Thrombolytic Evaluation Trial (EPITHET) and the Diffusion and Perfusion Imaging Evaluation for Understanding Stroke Evolution (DEFUSE) Study. Stroke 2011;42:1608-1614.

30 Leiva-Salinas C, Wintermark M: The future of stroke imaging: what we need and how to get to it. Stroke 2010;41(10 suppl):S152-S153.

31 Payabvash S, Souza LC, Wang Y, Schaefer PW, Furie KL, Halpern EF, et al: Regional ischemic vulnerability of the brain to hypoperfusion: the need for location specific computed tomography perfusion thresholds in acute stroke patients. Stroke 2011;42:12551260 .

32 von Kummer R, Weber J: Brain and vascular imaging in acute ischemic stroke: the potential of computed tomography. Neurology 1997;49(5 suppl 4):S52-S55.

-33 Arnold M, Nedeltchev K, Mattle HP, Loher TJ, Stepper F, Schroth G, et al: Intra-arterial thrombolysis in 24 consecutive patients with internal carotid artery T occlusions. J Neurol Neurosurg Psychiatry 2003;74:739-742.

34 Jansen O, von Kummer R, Forsting M, Hacke W, Sartor K: Thrombolytic therapy in acute occlusion of the intracranial internal carotid artery bifurcation. AJNR Am J Neuroradiol 1995;16:1977-1986.

35 Zaidat OO, Suarez JI, Santillan C, Sunshine JL, Tarr RW, Paras VH, et al: Response to intra-arterial and combined intravenous and intra-arterial thrombolytic therapy in patients with distal internal carotid artery occlusion. Stroke 2002;33:1821-1826.

36 Hacke W, Schwab S, Horn M, Spranger M, De Georgia M, von Kummer R: 'Malignant' middle cerebral artery territory infarction: clinical course and prognostic signs. Arch Neurol 1996;53:309-315.

37 Furlan A, Higashida R, Wechsler L, Gent M, Rowley $\mathrm{H}$, Kase $\mathrm{C}$, et al: Intra-arterial prourokinase for acute ischemic stroke. The PROACT II study: a randomized controlled trial. Prolyse in Acute Cerebral Thromboembolism. JAMA 1999;282:2003-2011.

38 Brandt T, von Kummer R, Muller-Kuppers M, Hacke W: Thrombolytic therapy of acute basilar artery occlusion. Variables affecting recanalization and outcome. Stroke 1996;27: 875-881.

-39 Angermaier A, Langner S, Kirsch M, Kessler C, Hosten N, Khaw AV: CT-angiographic collateralization predicts final infarct volume after intra-arterial thrombolysis for acute anterior circulation ischemic stroke. Cerebrovasc Dis 2011;31:177-184.

40 Bang OY, Saver JL, Buck BH, Alger JR, Starkman S, Ovbiagele B, et al: Impact of collateral flow on tissue fate in acute ischaemic stroke. J Neurol Neurosurg Psychiatry 2008;79:625-629.

41 Higashida RT, Furlan AJ, Roberts H, Tomsick $\mathrm{T}$, Connors B, Barr J, et al: Trial design and reporting standards for intra-arterial cerebral thrombolysis for acute ischemic stroke. Stroke 2003;34:e109-e137.

42 Ozdoba C, Sturzenegger M, Schroth G: Internal carotid artery dissection: MR imaging features and clinical-radiologic correlation. Radiology 1996;199:191-198.

43 Michel P, Ntaios G, Delgado MG, Bezerra DC, Meuli R, Binaghi S: CT angiography helps to differentiate acute from chronic carotid occlusion: the 'carotid ring sign'. Neuroradiology 2012;54:139-146.

44 Gacs G, Fox AJ, Barnett HJ, Vinuela F: CT visualization of intracranial arterial thromboembolism. Stroke 1983;14:756-762.

45 Launes J, Ketonen L: Dense middle cerebral artery sign: an indicator of poor outcome in middle cerebral artery area infarction. J Neurol Neurosurg Psychiatry 1987;50:1550-1552.

46 von Kummer R, Meyding-Lamade U, Forsting M, Rosin L, Rieke K, Hacke W, et al: Sensitivity and prognostic value of early CT in occlusion of the middle cerebral artery trunk. AJNR Am J Neuroradiol 1994;15:9-15; discussion 6-8.

47 Rovira A, Orellana P, Alvarez-Sabin J, Arenillas JF, Aymerich X, Grive E, et al: Hyperacute ischemic stroke: middle cerebral artery susceptibility sign at echo-planar gradient-echo MR imaging. Radiology 2004;232:466-473.

48 Riedel CH, Zimmermann P, Jensen-Kondering U, Stingele R, Deuschl G, Jansen O: The importance of size: successful recanalization by intravenous thrombolysis in acute anterior stroke depends on thrombus length. Stroke 2011;42:1775-1777.

49 Puetz V, Dzialowski I, Hill MD, Subramaniam S, Sylaja PN, Krol A, et al: Intracranial thrombus extent predicts clinical outcome, final infarct size and hemorrhagic transformation in ischemic stroke: the clot burden score. Int J Stroke 2008;3:230-236.

50 Hermier M, Nighoghossian N, Derex L, Wiart M, Nemoz C, Berthezene Y, et al: Hypointense leptomeningeal vessels at $\mathrm{T} 2{ }^{*}$-weighted MRI in acute ischemic stroke. Neurology 2005;65:652-653.

51 Morita N, Harada M, Uno M, Matsubara S, Matsuda T, Nagahiro S, et al: Ischemic findings of $2_{2}^{*}$-weighted 3-tesla MRI in acute stroke patients. Cerebrovasc Dis 2008;26: 367-375. 
52 Baik SK, Choi W, Oh SJ, Park KP, Park MG, Yang TI, et al: Change in cortical vessel signs on susceptibility-weighted images after full recanalization in hyperacute ischemic stroke. Cerebrovasc Dis 2012;34:206-212.

53 Latour LL, Kang DW, Ezzeddine MA, Chalela JA, Warach S: Early blood-brain barrier disruption in human focal brain ischemia. Ann Neurol 2004;56:468-477.
54 Hjort N, Wu O, Ashkanian M, Solling C, Mouridsen K, Christensen S, et al: MRI detection of early blood-brain barrier disruption: parenchymal enhancement predicts focal hemorrhagic transformation after thrombolysis. Stroke 2008;39:1025-1028

55 Fiehler J, Albers GW, Boulanger JM, Derex L, Gass A, Hjort N, et al: Bleeding risk analysis in stroke imaging before thromboLysis (BRASIL): pooled analysis of $\mathrm{T} 2{ }^{*}$-weighted magnetic resonance imaging data from 570 patients. Stroke 2007;38:2738-2744.
56 Viallon M, Altrichter S, Pereira VM, Nguyen D, Sekoranja L, Federspiel A, et al: Combined use of pulsed arterial spin-labeling and susceptibility-weighted imaging in stroke at 3T. Eur Neurol 2010;64:286-296.

57 Chng SM, Petersen ET, Zimine I, Sitoh YY, Lim CC, Golay X: Territorial arterial spin labeling in the assessment of collateral circulation: comparison with digital subtraction angiography. Stroke 2008;39:3248-3254. 